\title{
Experimental and Numerical Study of the Effect of Longitudinal Reinforcements on Cylindrical and Conical Absorbers under Impact Loading
}

\author{
Mohammad Damghani Nouri and Hossein Hatami* \\ Faculty of Mechanical Engineering, Semnan University, Semnan, Iran; h64hatami@gmail.com
}

\begin{abstract}
This article analyses the experimental and numerical tests of cylindrical and conical absorbers with longitudinal reinforcements under impact loading. Specimens were put under free fall loading by Drop Hammer and their energy absorption, initial peak force, average force, and crush length were calculated. Then, the obtained results were compared with the results of numerical tests. The results of experimental tests have an acceptable adaptation with numerical tests. Moreover, the number of reinforcements was a part of studied parameters and various parameters of these specimens were compared with the increasing number of reinforcements too. According to the results from the performed tests and simulations, crush length decreases and initial peak force increases with the increasing number of reinforcements. Among different specimens, cylindrical specimens have a lower crush length and a higher initial peak force compared with conical specimens with the same number of longitudinal reinforcements. Finally, by comparing the obtained results, it is concluded that the conical specimens are better energy absorbers under free fall loading compared with cylindrical specimens.
\end{abstract}

Keywords: Energy Absorption, Longitudinal Reinforcements, Impact Loading, Numerical Model

\section{Introduction}

Impact is a concept that is considered a disruptive factor in the industry. Thus, the control of this huge force in short time which sometimes is limited to milliseconds needs some solutions. In this regard, energy absorbers are used to control this sudden impact. Energy absorbers are used in various industries such as automotive and aerospace. Energy absorbers are also used to reduce the damages of collisions and sudden impacts. Therefore, many studies have been done on this seemingly simple part.

In recent years, these structures are used in the automotive industry as absorber and energy absorbers. The reason is their low weight along with their mechanical properties and structural advantages. Thin-walled structures have many applications in the manufacturing of motorized vehicles such as cars, trains, ships and many other devices ${ }^{1}$. They have a high popularity in the market due to low weight, low cost and high energy absorption properties. Thus, energy absorption is an important subject in the industry for eliminating the collision energy and protecting equipment and structures ${ }^{2}$. In this subject, the kinetic energy of collision should be converted into other energies. In fact, this is an irreversible reaction.

In recent decades, several tests have been done on thinwalled structures for calculating the absorbed energy value such as axial and bending loadings, and oblique impacts on different specimens. A study was done on low-carbon steel specimens under axial loadings for finding different modes of deformation on thin-walled specimens ${ }^{3}$. Abramowicz et al. conducted research on the collapse mechanisms of thin-walled columns ${ }^{4,5}$. They then compared the obtained

${ }^{*}$ Author for correspondence 
theoretical results with experimental studies ${ }^{6,7}$. Nagel et al. performed a numerical modeling on thin-walled conical sections under axial and oblique loadings and examined the obtained energy absorption ${ }^{8,9}$. Hanssen studied the aluminum columns filled with foam under compression loading. He compared energy absorption values for various parameters ${ }^{10}$. Reyes et al. studied the same specimens under oblique compression loading numerically and experimentally ${ }^{11}$. Olabi conducted extensive research on metallic tubes using the three experimental, numerical and analytical methods. He also applied axial, bending and oblique loadings and finally came to the conclusion that in recent studies, the industry needs absorbers that can be more resistant against impact loading and this occurs by changing material or deformation of absorbers ${ }^{12}$.

In recent decades, powerful finite element analyses have been carried out on energy absorption structures. This method has a faster and cheaper analysis than experimental methods and much research has been done in this field ${ }^{2,13}$. In these numerical methods, the objective is to optimize the effective energy absorption coefficient. By changing energy absorption structures in numerical methods, the most optimal state can be achieved.

One of the most important factors in choosing a good energy absorber is low initial peak force in the force-displacement curve. In the following studies, it is attempted to make changes in the structure geometry so that the structure has the initial geometric imperfection and the initial buckling occurs in it under impact loading, such as creating plans on absorbent plate ${ }^{1}$, creating grooves ${ }^{14,15}$, stretching bars ${ }^{16,17}$, creating corners and dents ${ }^{18}$.

In all previous studies, most numerical and experimental tests were carried out on quasi-static loadings and the dynamic test results, especially impact is very low. In this study, numerical and experimental tests are done under impact loading. Moreover, the effect of their longitudinal reinforcements is also evaluated so that the energy absorption values of different specimens can be compared under free fall loading.

\section{Experimental Tests}

Impact test apparatus consists of an impacting mass with $150 \mathrm{~kg}$ capacity (Figure 1). In free fall, the impacting mass collides the specimens (maximum lift height of the impacting mass is $2.5 \mathrm{~m}$ ). Accelerometer sensors are attached on the impacting mass and the load cell under the plate of specimens. Their data are entered into the processing system of the apparatus, so we will have acceleration-time and energy-time curves.

\subsection{Geometry and Mechanical Properties of Specimens}

The geometrical dimensions of specimens are given in Table 1. ' $\mathrm{S}$ ' is a symbol of cylindrical specimens and ' $\mathrm{C}$ ' is a symbol of conical specimens. The number before the symbol represents the number of longitudinal reinforcements attached to them.

Mechanical properties of the specimens are given in Table 2.

The stress-strain curve for the simple tensile test of the specimens is shown in Figure 2. The specimens are made of alloy steel.

The specimens prepared for testing are shown in Figure 3. Cylindrical and conical specimens are with and without longitudinal reinforcement.

\subsection{Test Conditions and Calculating Energy Absorption}

With a mass of $90 \mathrm{~kg}$ and a height of $2 \mathrm{~m}$, the impacting mass collides the desired specimen. The specimen end is fixed from bottom by the load cell and the plate between them.

To obtain the absorbed energy, the area under the force-displacement curve must be calculated. The trapezoidal method is used for calculating the area under

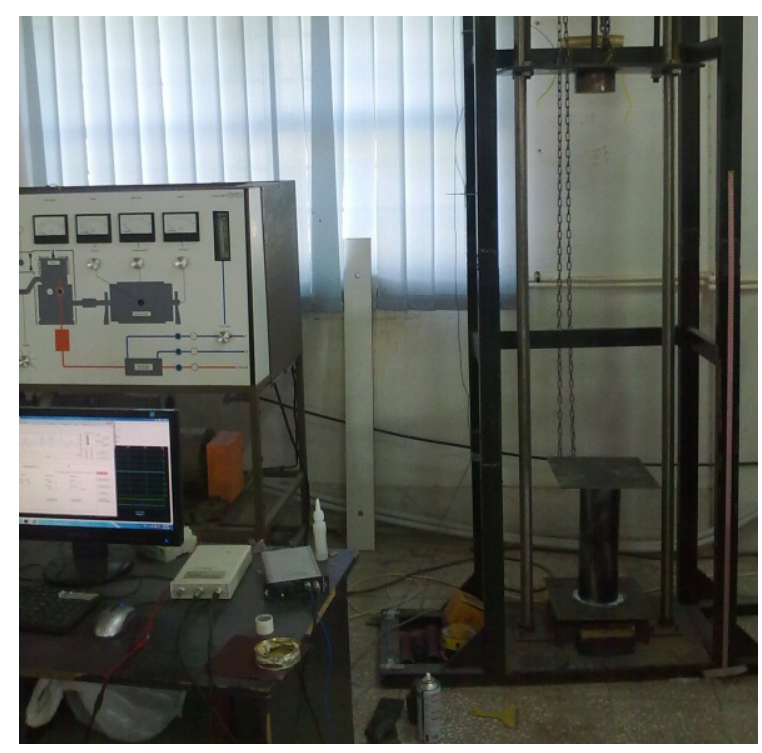

Figure 1. Impact test apparatus. 
Table 1. Geometry of specimens

\begin{tabular}{lcccccc}
\hline$t$ & wing width & $\alpha$ & $\mathrm{d}$ & D & length & specimen \\
\hline $0.02 \mathrm{~cm}$ & - & - & - & $7 \mathrm{~cm}$ & $12 \mathrm{~cm}$ & $\mathrm{~S} 0$ \\
$0.02 \mathrm{~cm}$ & $1.7 \mathrm{~cm}$ & - & - & $7.1 \mathrm{~cm}$ & $12.1 \mathrm{~cm}$ & $\mathrm{~S} 2$ \\
$0.02 \mathrm{~cm}$ & $1.75 \mathrm{~cm}$ & - & - & $6.85 \mathrm{~cm}$ & $12.1 \mathrm{~cm}$ & $\mathrm{~S} 3$ \\
$0.02 \mathrm{~cm}$ & $1.7 \mathrm{~cm}$ & - & - & $7.2 \mathrm{~cm}$ & $12 \mathrm{~cm}$ & $\mathrm{~S} 4$ \\
$0.02 \mathrm{~cm}$ & - & $8.29^{*}$ & $3.5 \mathrm{~cm}$ & $7 \mathrm{~cm}$ & $12 \mathrm{~cm}$ & $\mathrm{C} 0$ \\
$0.02 \mathrm{~cm}$ & $1.65 \mathrm{~cm}$ & $8.57^{*}$ & $3.55 \mathrm{~cm}$ & $7.2 \mathrm{~cm}$ & $12.1 \mathrm{~cm}$ & $\mathrm{C} 2$ \\
$0.02 \mathrm{~cm}$ & $1.75 \mathrm{~cm}$ & $8.6^{*}$ & $3.6 \mathrm{~cm}$ & $7.2 \mathrm{~cm}$ & $11.9 \mathrm{~cm}$ & $\mathrm{C} 3$ \\
$0.02 \mathrm{~cm}$ & $1.8 \mathrm{~cm}$ & $8.71^{*}$ & $3.4 \mathrm{~cm}$ & $7.2 \mathrm{~cm}$ & $12.4 \mathrm{~cm}$ & $\mathrm{C} 4$ \\
\hline
\end{tabular}

Table 2. Mechanical properties of specimens

\begin{tabular}{lc}
\hline Parameter & Measurement \\
\hline Density & $2700 \mathrm{Kg} / \mathrm{m}^{3}$ \\
Yield stress & $129.7 \mathrm{MPa}$ \\
Ultimate stress & $203.4 \mathrm{MPa}$ \\
Yang modulus & $70 \mathrm{GPa}$ \\
Poison ratio & 0.3 \\
\hline
\end{tabular}

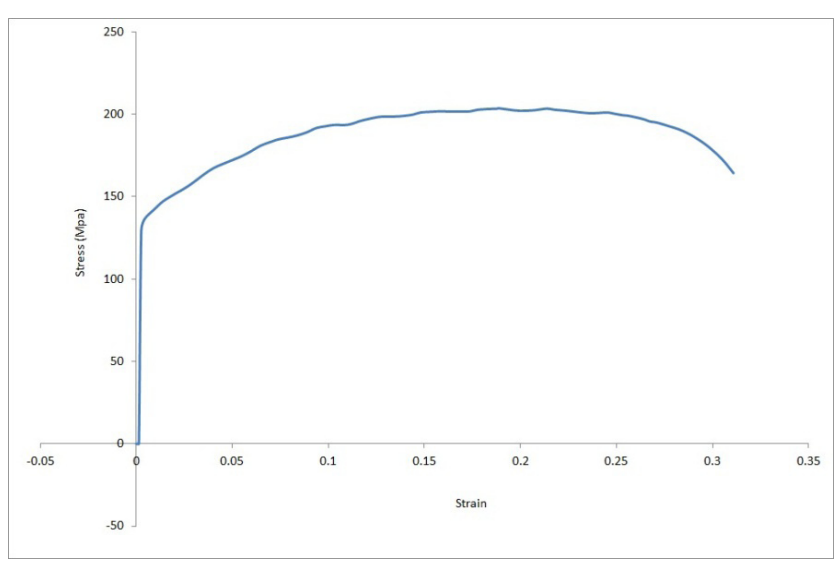

Figure 2. Stress-strain curve.

the acceleration-time curve and converting it to the displacement-time curve. The error order in this integration method is the second order which is a good accuracy:

$$
\mathrm{s}=\sum_{\mathrm{i}}^{\mathrm{n}} \frac{1}{2\left(\mathrm{x}_{\mathrm{i}+1}-\mathrm{x}_{\mathrm{i}}\right)} *\left(\mathrm{y}_{\mathrm{i}+1}+y_{\mathrm{i}}\right)
$$

where, "i" is the collision time of the impacting mass with the specimen, $\mathrm{n}$ is the time for the impacting mass to reach the specimen end. And timeframes depend on high precision of the accelerometer, i.e. it can receive how much data in the short impact timeframe from the test.

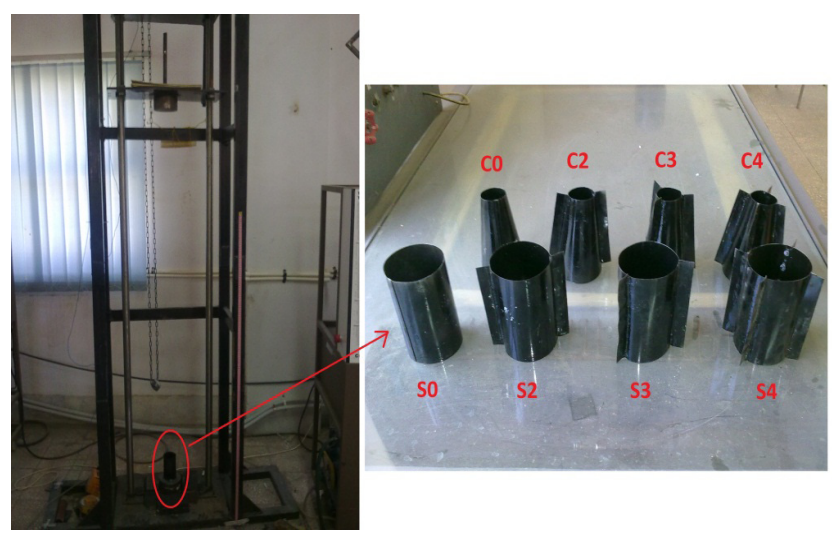

Figure 3. Naming of test specimens.

\subsection{Experimental Results}

Acceleration-time graphs for the test specimens are shown in Figures 4 to 11. First, cylindrical specimens are tested in order of the number of longitudinal reinforcements. Then, conical specimens are tested under impact loading. From test specimens and acceleration-time curves, it can be said that with an increase in the number of longitudinal reinforcements, according to the deformed specimens, the crush length significantly decreased. Longitudinal reinforcements lead to asymmetric collapse. The slowing acceleration value greatly increases when 

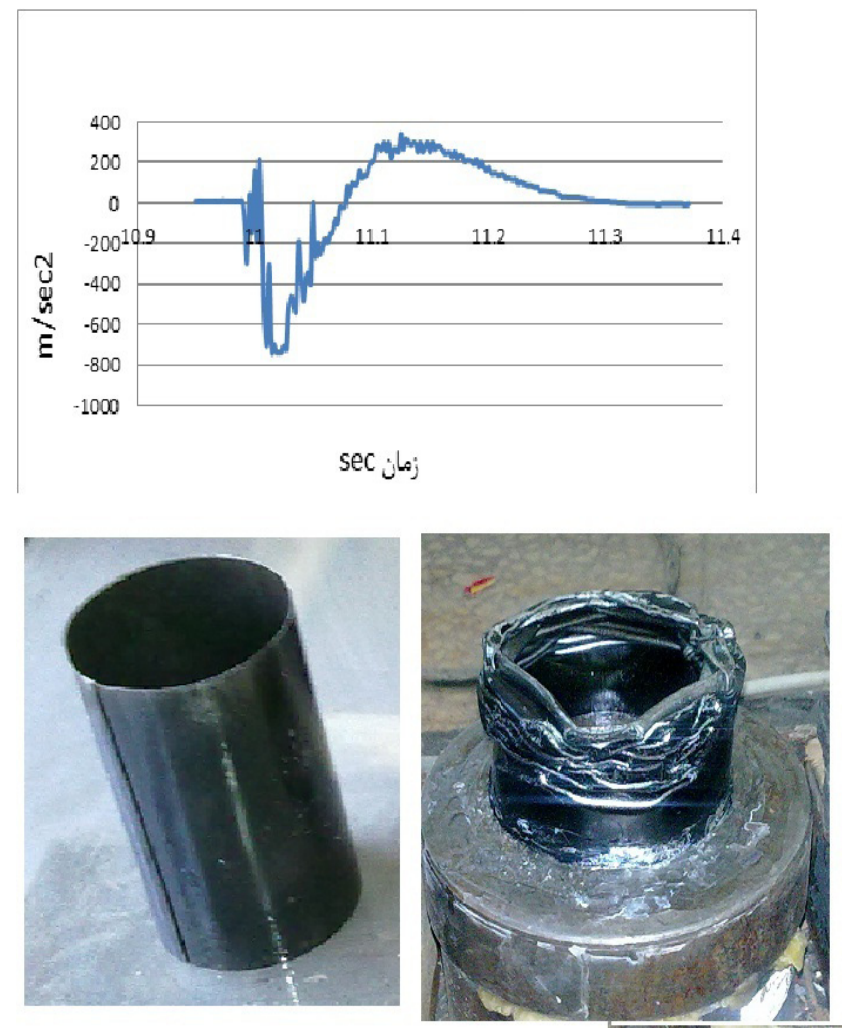

Figure 4. Acceleration-time curve of S0.
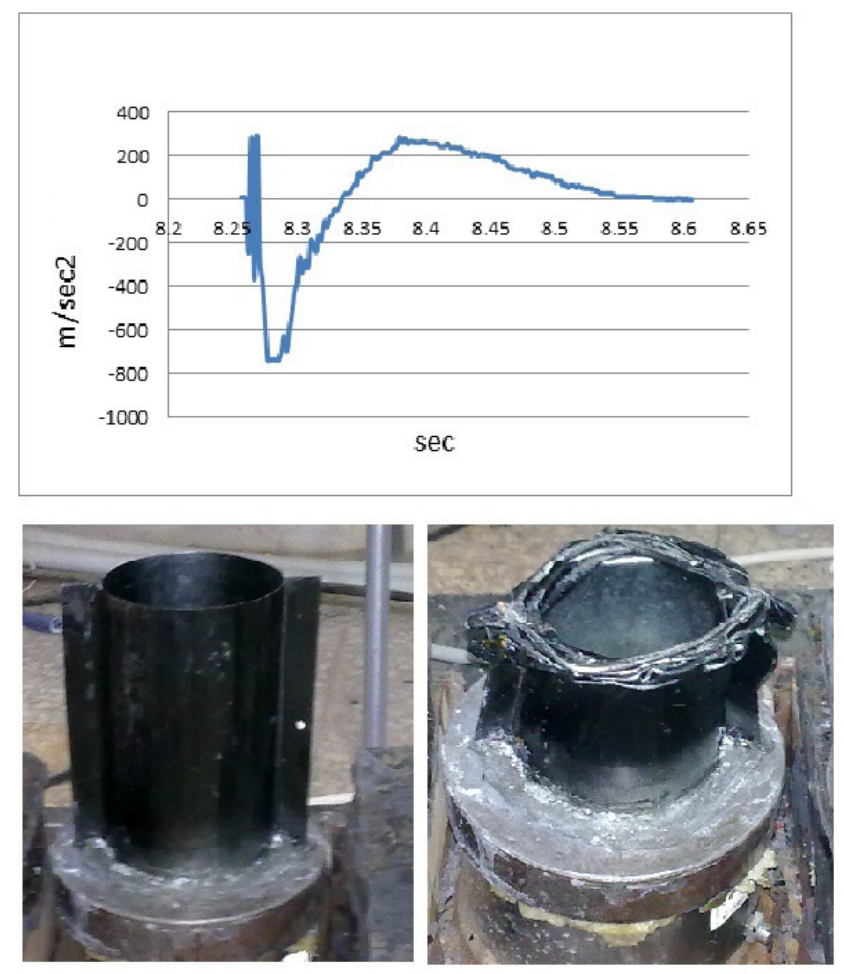

Figure 5. Acceleration-time curve of S2.

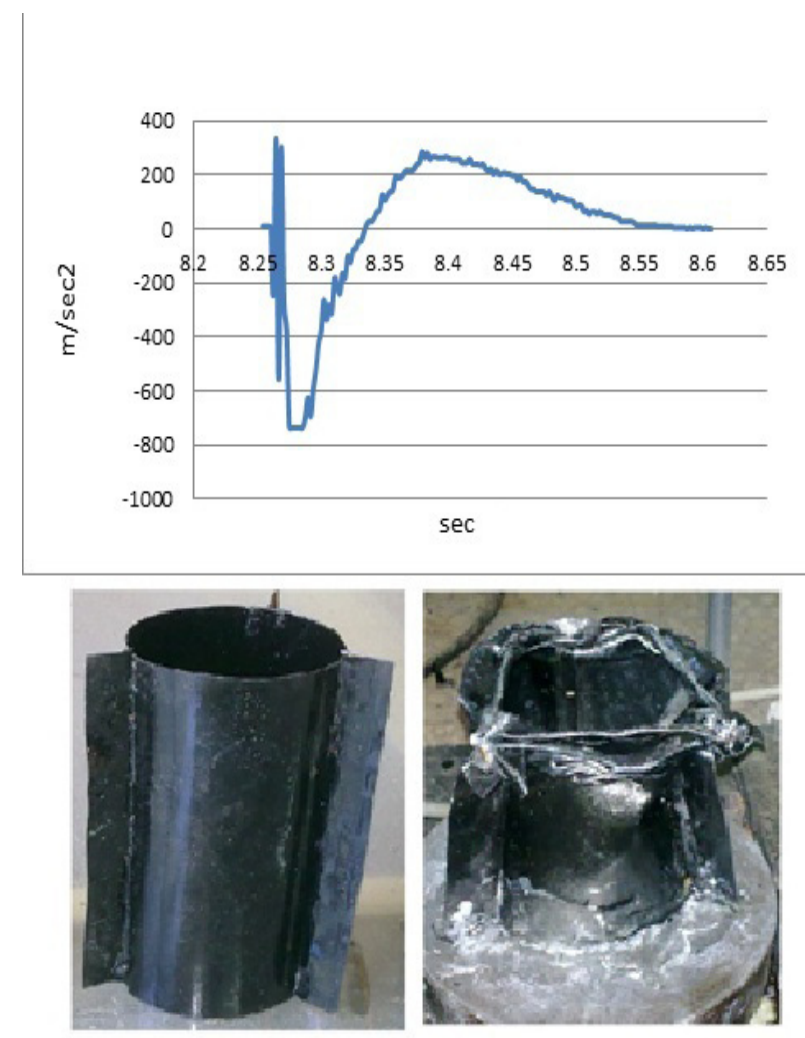

Figure 6. Acceleration-time curve of S3.

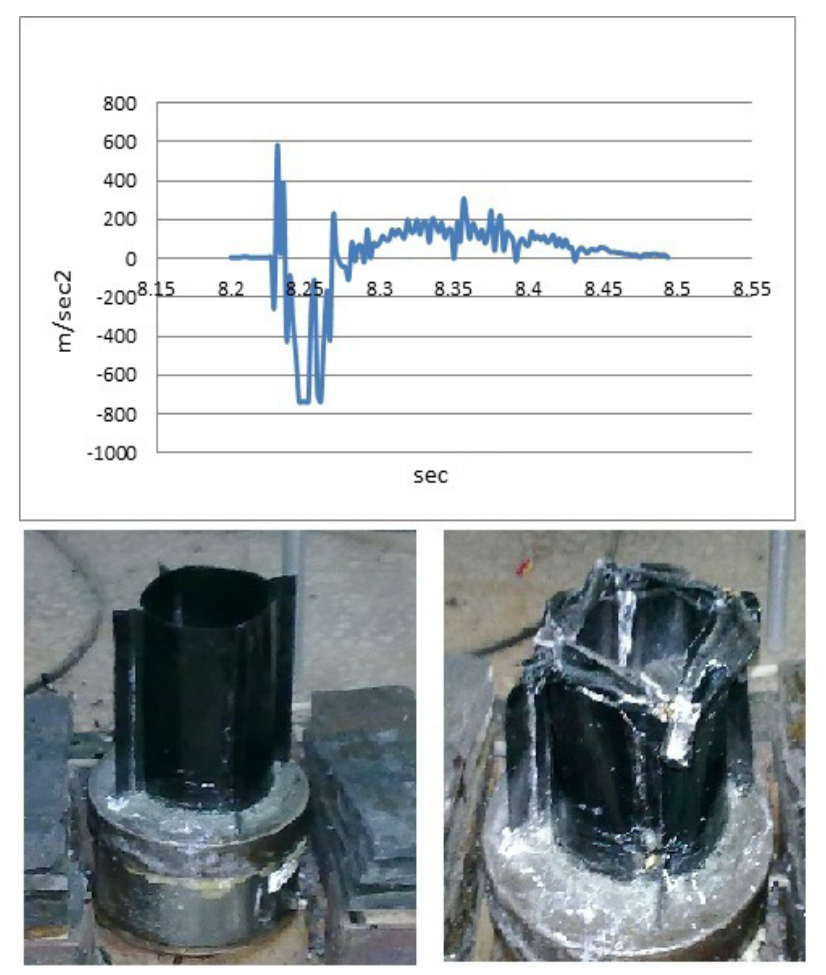

Figure 7. Acceleration-time curve of S4. 

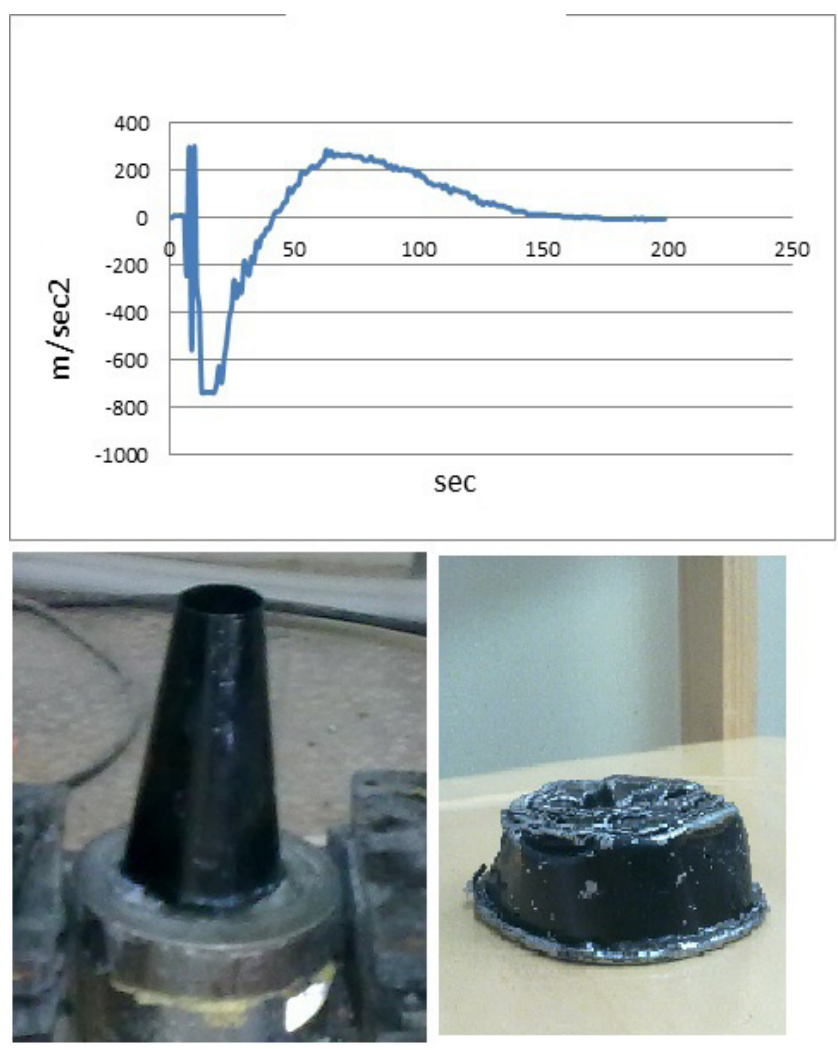

Figure 8. Acceleration-time curve of $\mathrm{C} 0$.

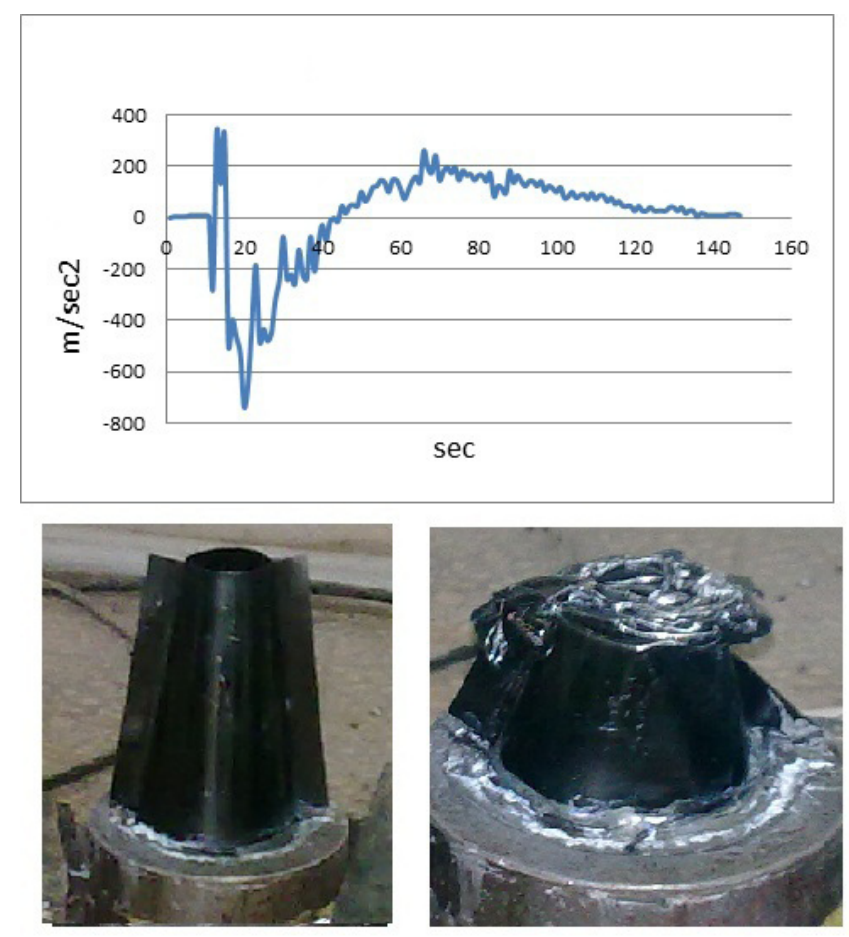

Figure 9. Acceleration-time curve of C2.
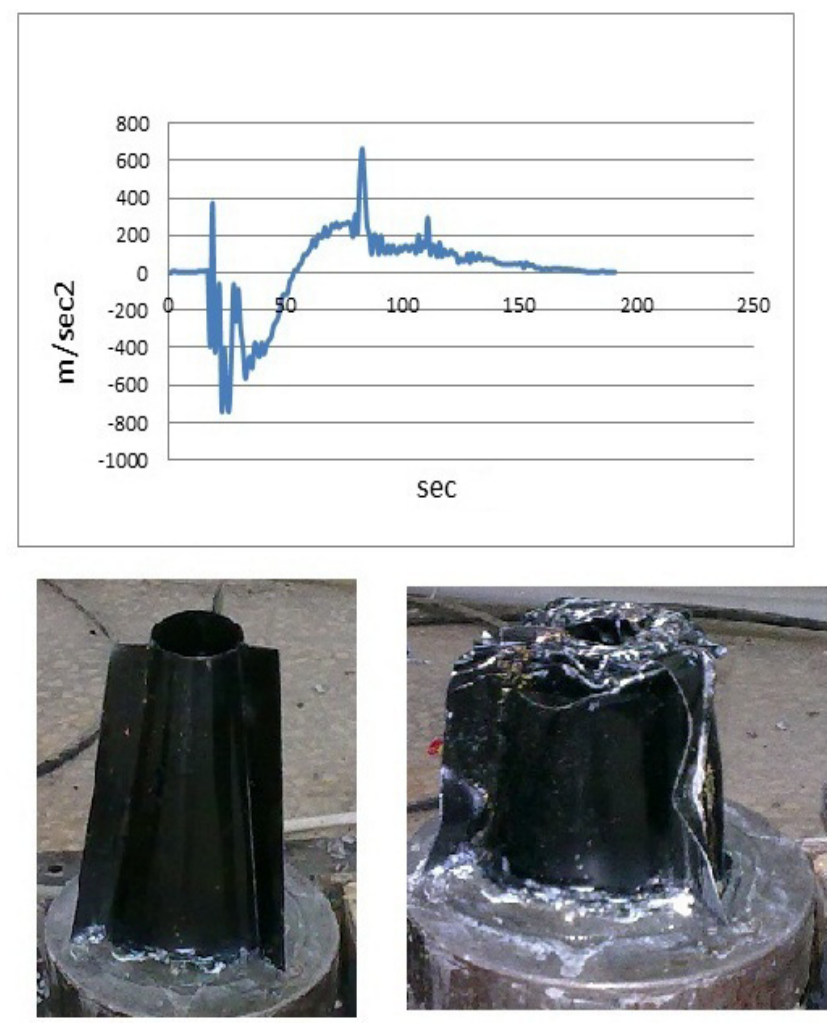

Figure 10. Acceleration-time curve of C3.

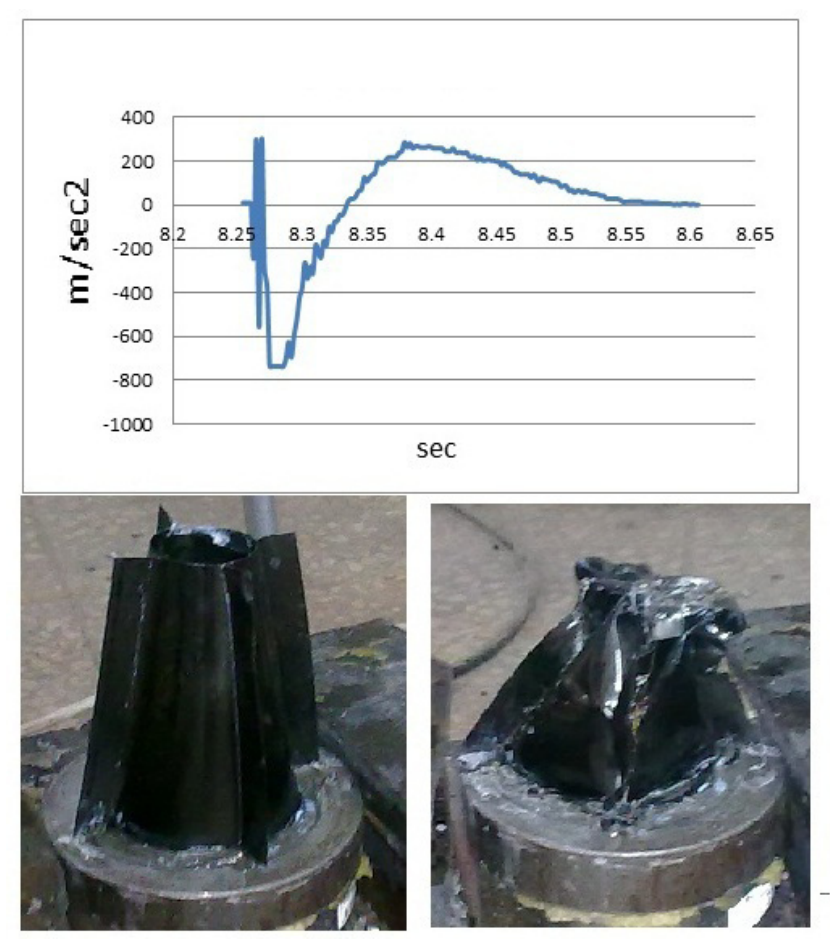

Figure 11. Acceleration-time curve of C4. 
the impacting mass collides the specimens. Then, it has fluctuations due to created wrinkling. Finally, the acceleration value exceeds zero and becomes slightly positive with a decrease in the impact kinetic energy until the full stop of the impacting mass. This is due to the return of the impacting mass after full collision with the specimen. This part of the curve is ignored in computing the absorbed energy value. Millisecond is time-precision of acceleration sensor and in some tests, the time curve is set in milliseconds.

Energy absorption value in experimental impact tests is calculated from the potential energy of the impacting mass placed at height $\mathrm{H}$. For the tests performed in this study, the energy value for a $90 \mathrm{~kg}$ mass at height $\mathrm{H}$ is calculated below.

$$
\mathrm{mgh}=90 * 10 * 2=1800 \mathrm{j}
$$

According to the law of energy conservation, if the waste energy during the free fall of the impacting mass before collision with the specimen surface is ignored, the impacting mass velocity when touching the specimen surface is given by:

$$
\mathrm{mgh}=\frac{1}{2} \mathrm{mV}^{2} \rightarrow \mathrm{V}=\sqrt{(2 \mathrm{gh})} \rightarrow \mathrm{V}=6.32 \frac{\mathrm{m}}{\mathrm{s}}
$$

The parameters that were observed in experimental tests and then will be compared with numerical results include crush length, velocity changes, acceleration changes and the displacement-force curve. The collapse shape of specimens will be compared experimentally and numerically.

\section{Numerical Results}

Next, the test specimens are simulated by ABAQUS and are compared by increasing their longitudinal reinforcements. Like experimental tests, simulations are carried on cylindrical and conical specimens. Then, energy absorption, crush and collapse values of specimens are compared with experimental results.

First, a buckling test should be done on each model so that the first buckling mode is obtained. Since the collapse probability according to the first buckling mode increases in experimental tests, the collapse probability under the first buckling mode must be increased in the default definition section in the impact simulation. To define this section in ABAQUS, the buckling of models is done first. They are placed under the first buckling modes of specimens in Figure 12. Before simulating the model, the following code lines are added in the model coding so that buckling simulation results are used when simulating the impact.

*node output

$\mathrm{u}$,

*node file, global=yes

$\mathrm{u}$,

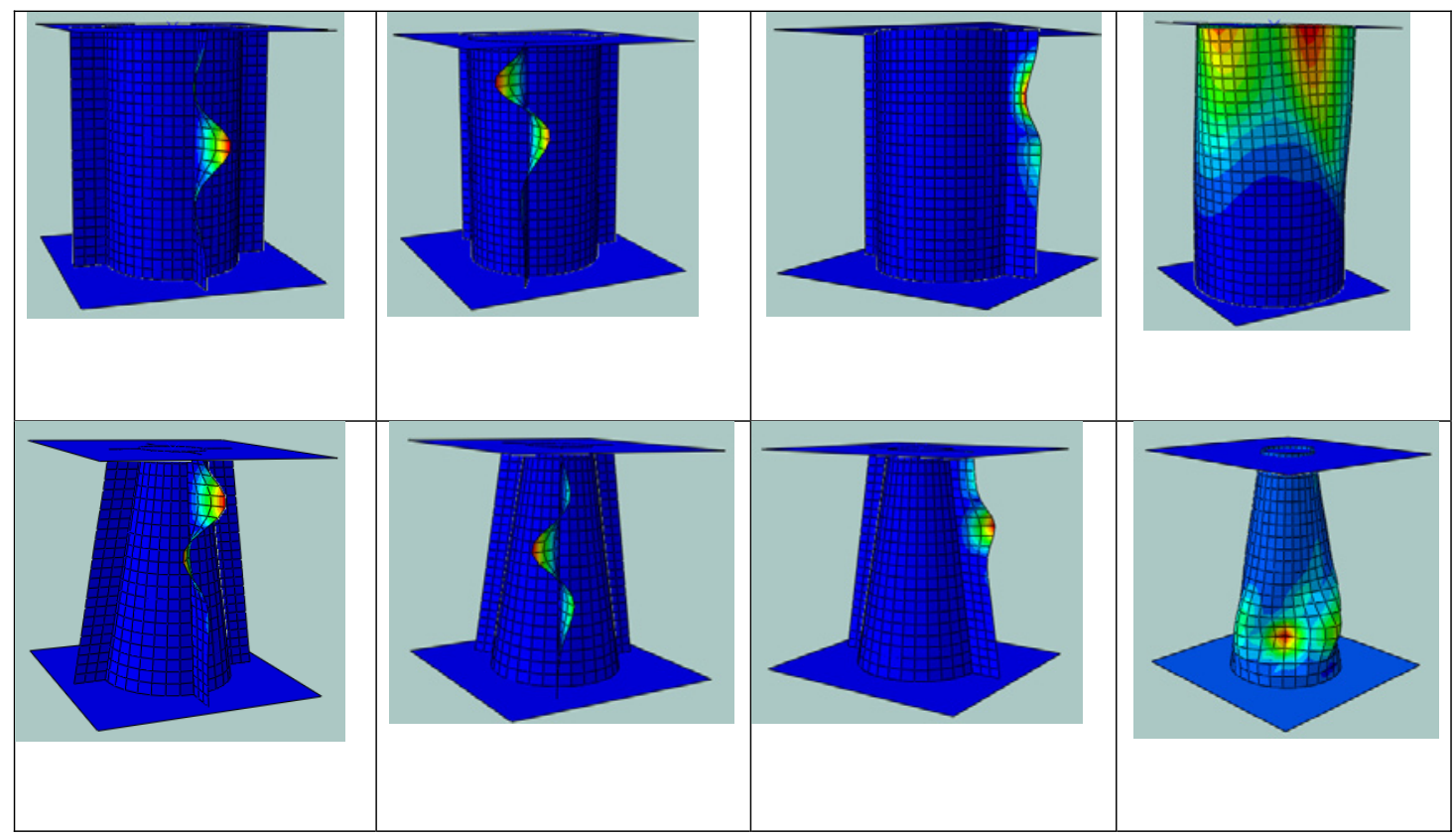

Figure 12. First buckling mode for various models. 
Then after buckling simulation of models, the following code is applied as the buckling imperfection of the first mode in the coding of impact simulation before simulation and then, the simulation is performed.

*Imperfection, FILE=Name of Buckling Job , step=1

$1,1 \mathrm{e}-4$

$2,1 \mathrm{e}-5$

$3,1 \mathrm{e}-6$

4,1 e-7

By adding a few code lines, the occurrence probability of the first buckling mode will increase in each impact loading.

In the following figure, the impacting mass of acceleration-time, the specimen crush length-time and the
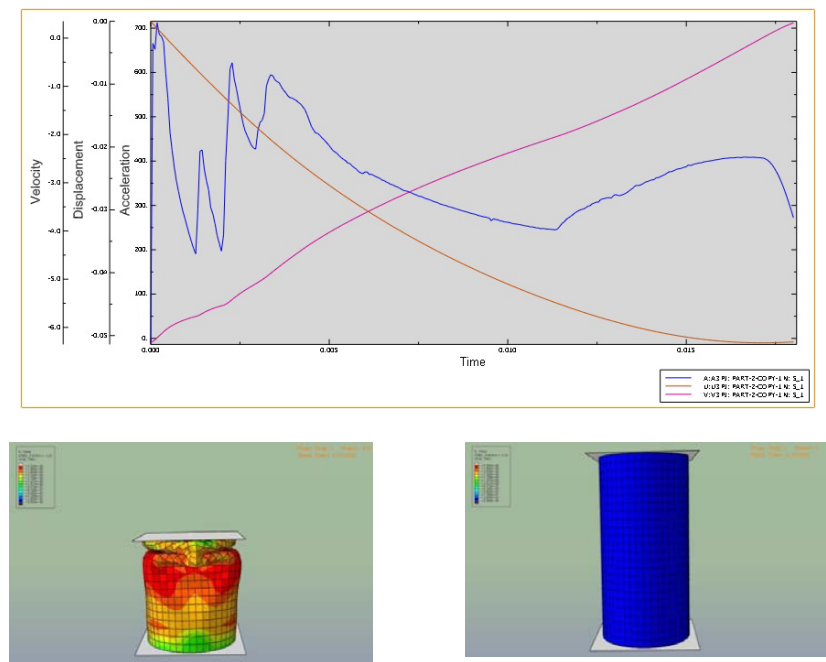

Figure 13. Acceleration, displacement, velocity curves and the $\mathrm{S} 0$ model before and after loading.
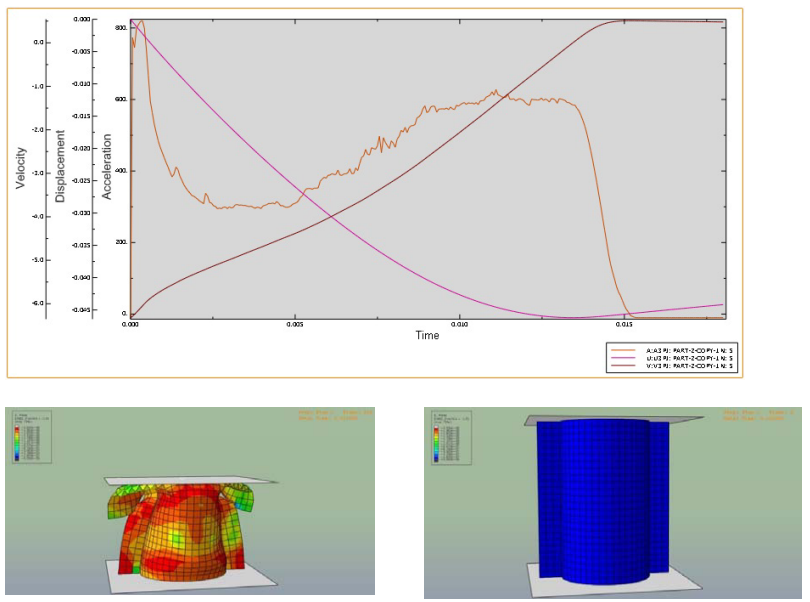

Figure 14. Acceleration, displacement, velocity curves and the $\mathrm{C} 4$ model before and after loading. impacting mass velocity-time curves are shown. Next, the collapse shape of the models before and after the impact test is shown. Finally, the reaction force-time curves are presented (Figures 13-20).

\subsection{Comparison of Crush Length}

In acceleration-time curves shown above, after the collision of the impacting mass with the specimen surfaces, suddenly the acceleration direction changes from the free fall acceleration value and a very high slowing acceleration value occurs. Thus, the calculated collision velocity $(6.32$ $\mathrm{m} / \mathrm{s}$ ) moves towards zero in velocity-time curve. When both the slowing acceleration and the impact velocity are
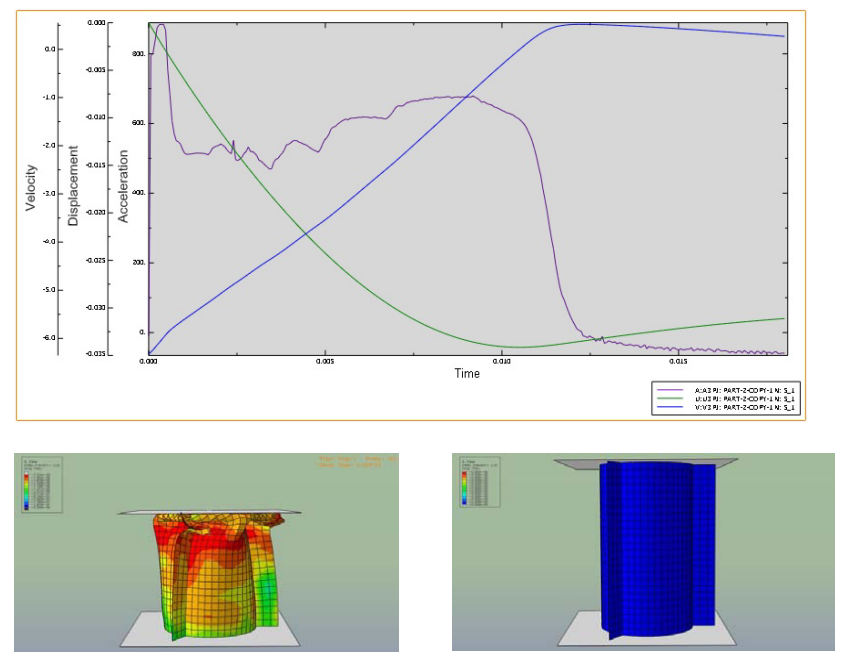

Figure 15. Acceleration, displacement, velocity curves and the $\mathrm{S} 3$ model before and after loading.
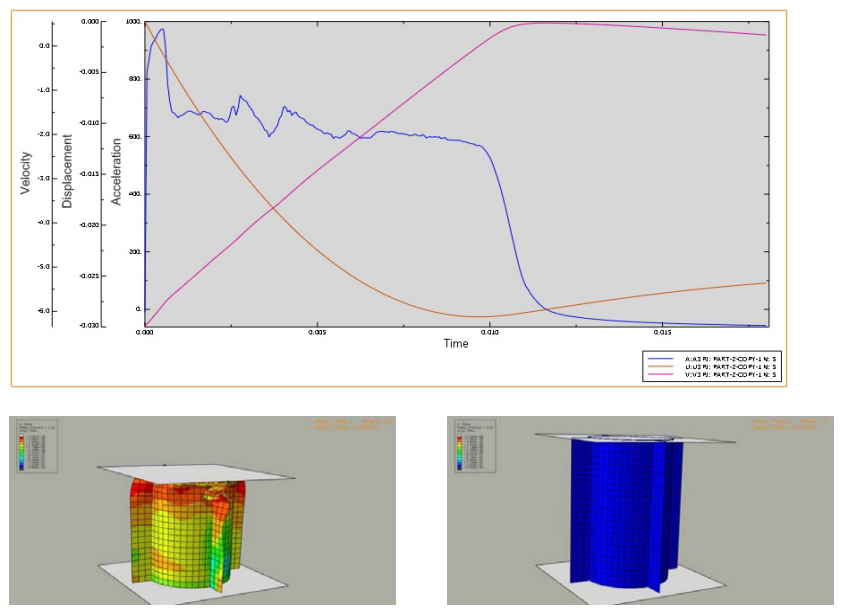

Figure 16. Acceleration, displacement, velocity curves and the $\$ 4$ model before and after loading. 


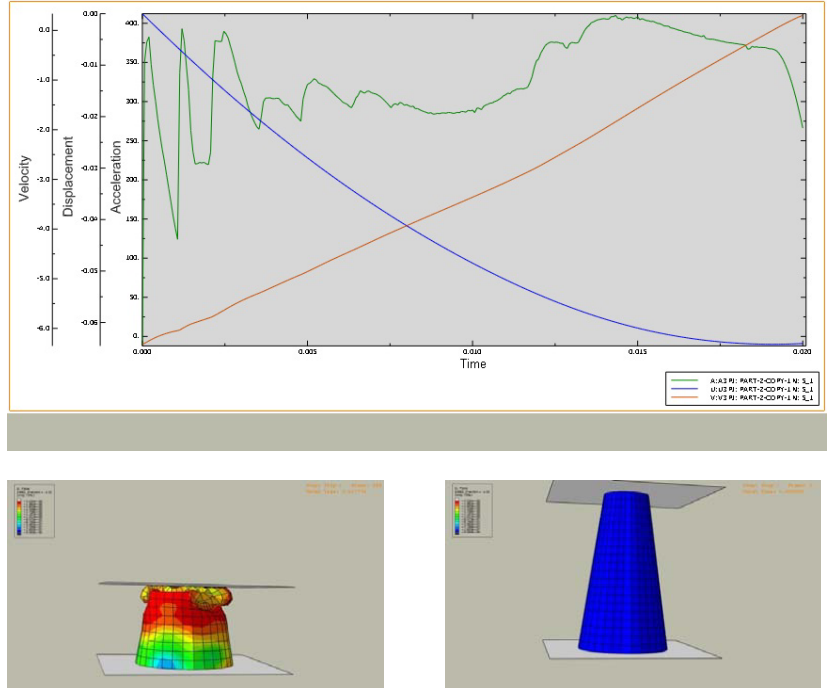

Figure 17. Acceleration, displacement, velocity curves and the $\mathrm{C} 0$ model before and after loading.
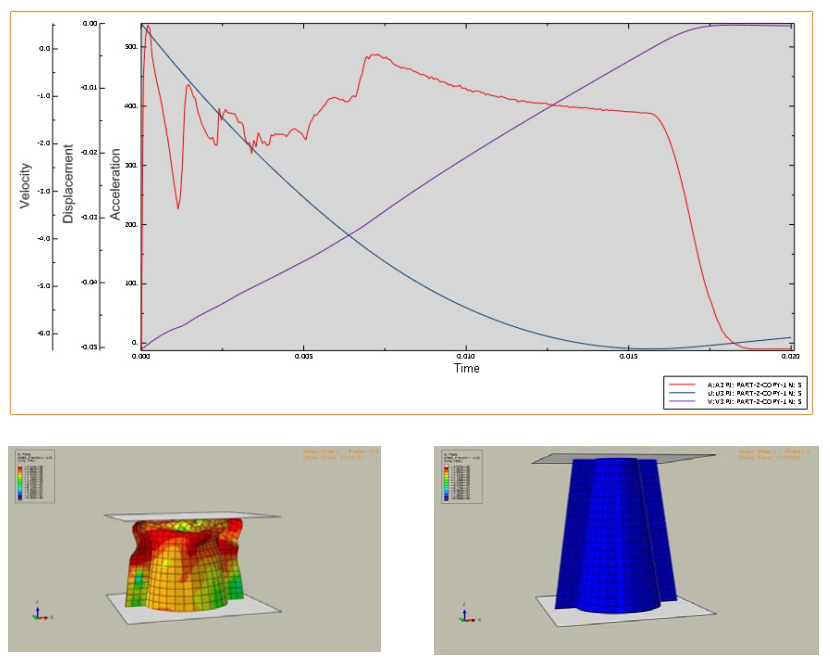

Figure 18. Acceleration, displacement, velocity curves and the $\mathrm{C} 2$ model before and after loading.

reduced, crush length increases. The final crush values for various models are shown in Table 3.

The results in Table 3 indicate that with an increase in number of longitudinal reinforcements, crush length is significantly decreased. The crush length of conical models is higher than cylindrical model with the same number of reinforcements. In the discussion of quasistatic loadings, with an increase in the crush length under the same loading velocity, the greater the crush length, the tested specimen is considered a more appropriate energy absorber. But in impact loading, since the absorbed energy is equal in the test specimens of a same
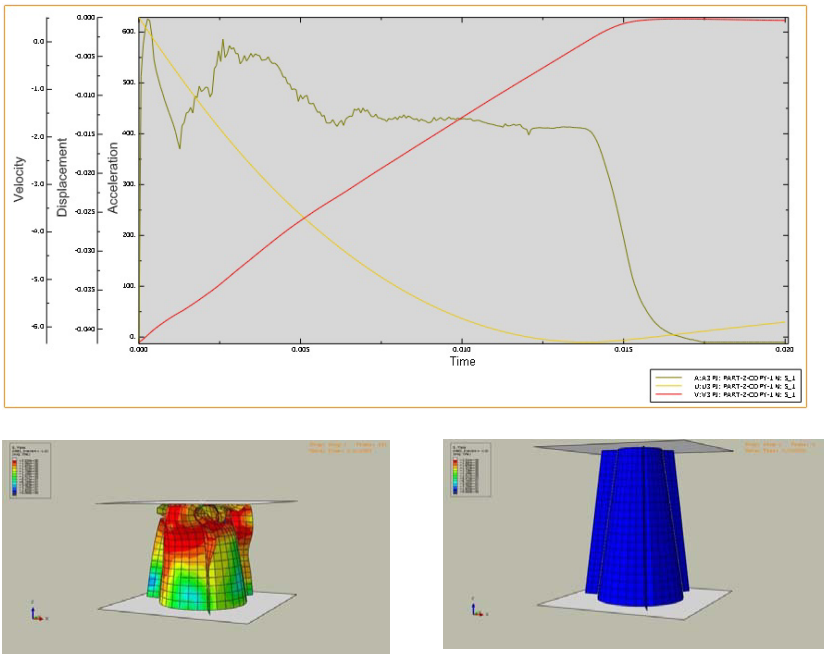

Figure 19. Acceleration, displacement,velocity curves and the $\mathrm{C} 3$ model before and after loading.
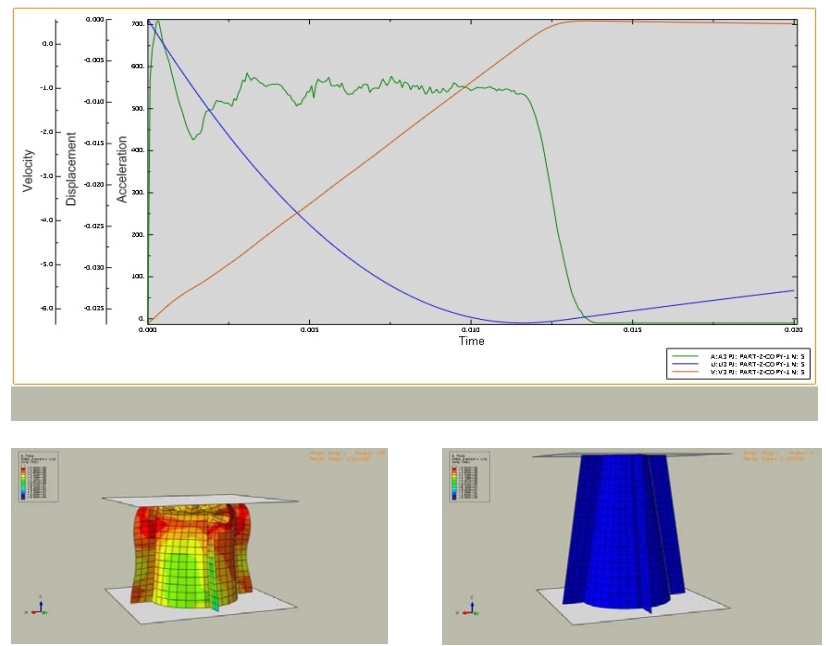

Figure 20. Acceleration, displacement, velocity curves and the $\mathrm{C} 4$ model before and after loading.

material, the greater the crush length of the specimen, it is considered as a more appropriate energy absorber. Therefore, by observing the crush length results in the table above, cylindrical specimens under impact loadings are better absorbers than conical specimens. Now, the initial peak force parameter must be studied in the test specimens. The initial peak force is a sensitive parameter in choosing a good energy absorber, because if the initial peak force created in the force-displacement curve of an absorber decreases and the energy absorption remains the same, then that specimen is selected as a suitable absorber. 


\subsection{Comparison of the Force-displacement} Curves and the Initial Peak Force Value

In the following Figures, the support force-crush length curves are given for different models. The energy value under the force-displacement curve is calculated and compared with the initial value of impact energy.

The absorbed energy value in the simulated models according to the force-displacement curves (shown in Figures 21 to 28 ) is equal to the absorbed energy value in experimental results calculated in the above equation (1800 J). This small calculated difference is due to integration errors for calculating the area under the forcedisplacement curve. Thus, the free-fall kinetic energy is converted into the energy value for plastic deformation of absorbers.

In the Table 4, the initial peak force of simulated models are compared with each other.

From the results of the above table, it can be seen that cylindrical models have a higher peak force than conical models with the same number of longitudinal reinforcements. Moreover, with an increase in the number of longitudinal reinforcements, the initial peak is significantly

Table 3. Crush length values of models

\begin{tabular}{lccccccc} 
C4 & C3 & C2 & C0 & S4 & S3 & S2 & S0 \\
\hline 3.32 & 4.15 & 5.01 & 6.41 & 2.88 & 3.39 & 4.59 & 5.11 \\
\hline
\end{tabular}

increased. Thus, the initial peak force parameter is inversely related to the crush length value according to these results because the model geometry leads to collision and high initial peak force. Therefore, the specimen resistance against crush length decreases. Thus, among test specimens, the optimum specimen must be found which has a lower crush length with a lower initial peak force. A lower crush length is considered for selecting a good absorber in impact loading because the absorbed energy value is the same for all absorbers. Therefore, a specimen that has a lower deformation will be more appropriate. Next, we compare the average force in simulated specimens as another key parameter.

\subsection{Comparison of the Average Force Parameter in the Force-displacement Curves}

To calculate the average force of the force-displacement curve, we divide total force from the simulation results by the number of these points so that the average force value for each simulation is obtained. In Table 5, average force values are calculated for each model.

Table 4. Initial peak power models under free fall loading $(\mathrm{kN})$

\begin{tabular}{lccccccc}
\hline C4 & C3 & C2 & C0 & S4 & S3 & S2 & S0 \\
\hline 66.77 & 57.33 & 51.22 & 44.95 & 90.91 & 83.84 & 77.14 & 65.31 \\
\hline
\end{tabular}

Table 5. Average force of force-displacement curves $(\mathrm{kN})$

\begin{tabular}{lccccccc}
\hline C4 & C3 & C2 & C0 & S4 & S3 & S2 & S0 \\
\hline 57.20 & 41.20 & 36.73 & 30.72 & 59.88 & 58.95 & 42.64 & 34.11 \\
\hline
\end{tabular}

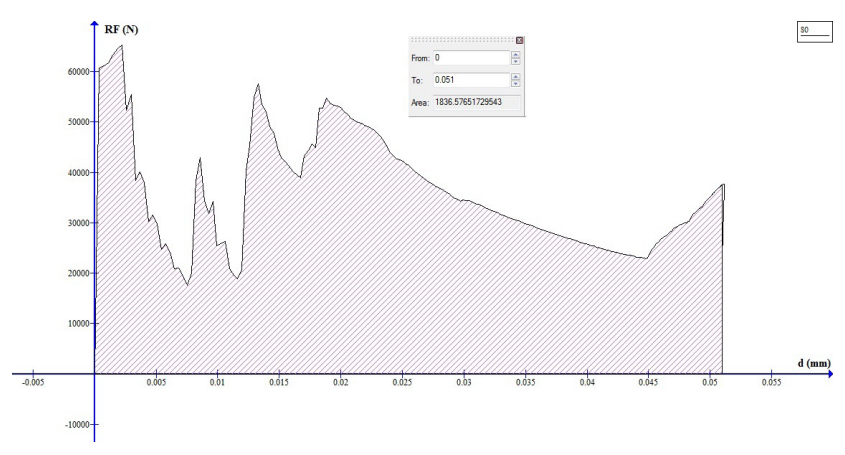

Figure 21. Force-displacement curve of S0.

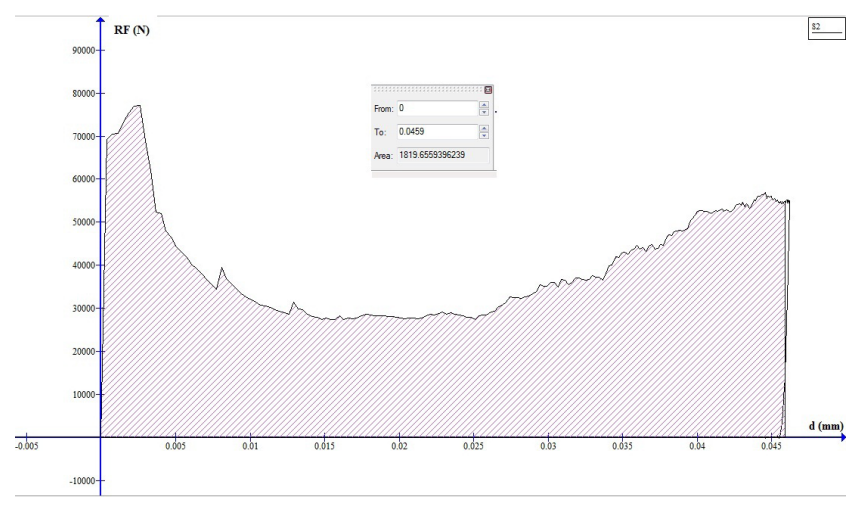

Figure 22. Force-displacement curve of S2. 


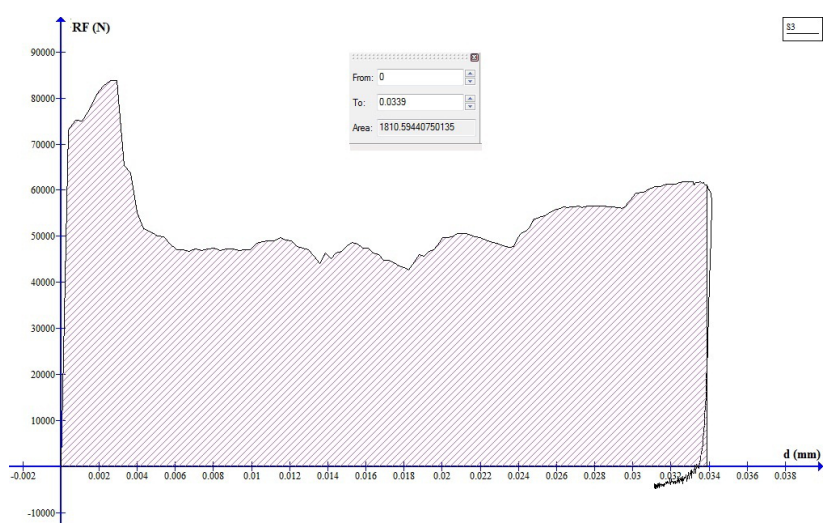

Figure 23. Force-displacement curve of S3.

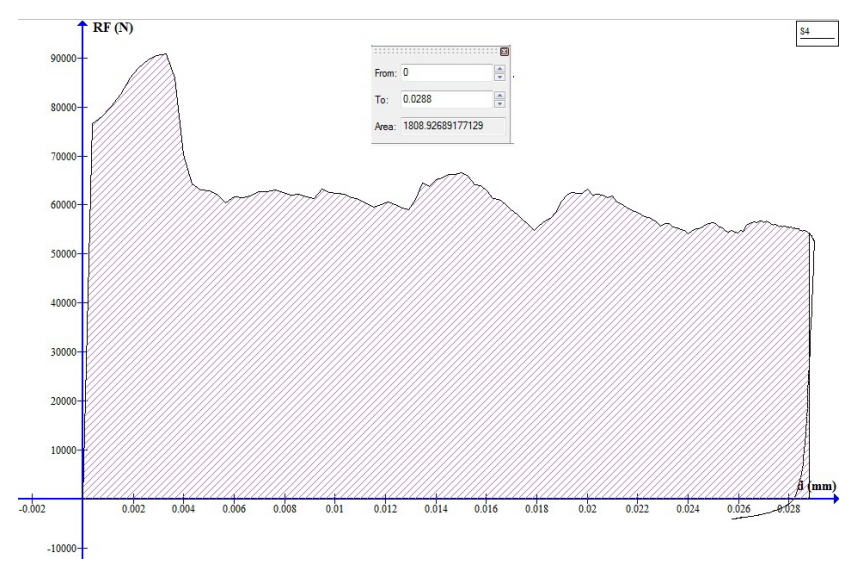

Figure 24. Force-displacement curve of S4.

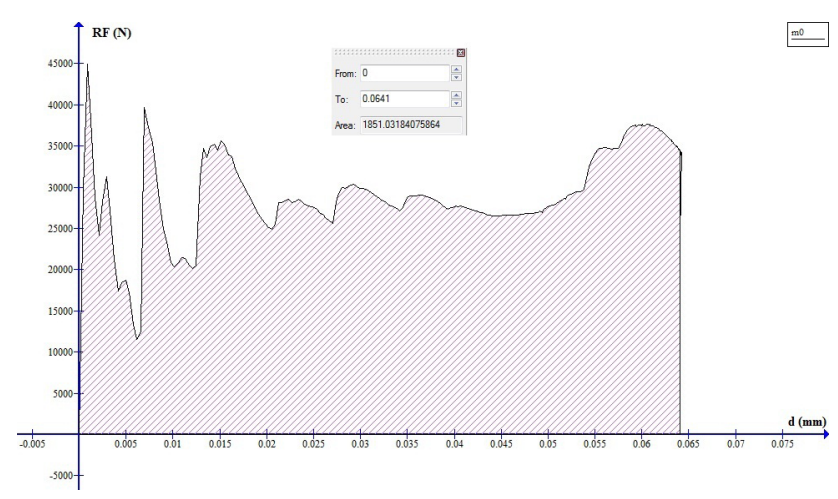

Figure 25. Force-displacement curve of C0.

According to the above table, the average force of cylindrical specimens is higher than conical ones with the same number of reinforcements. Moreover, with an increase in the number of reinforcements, the average force increases. But among the three critical parameters (crush length, initial peak force and the average force of

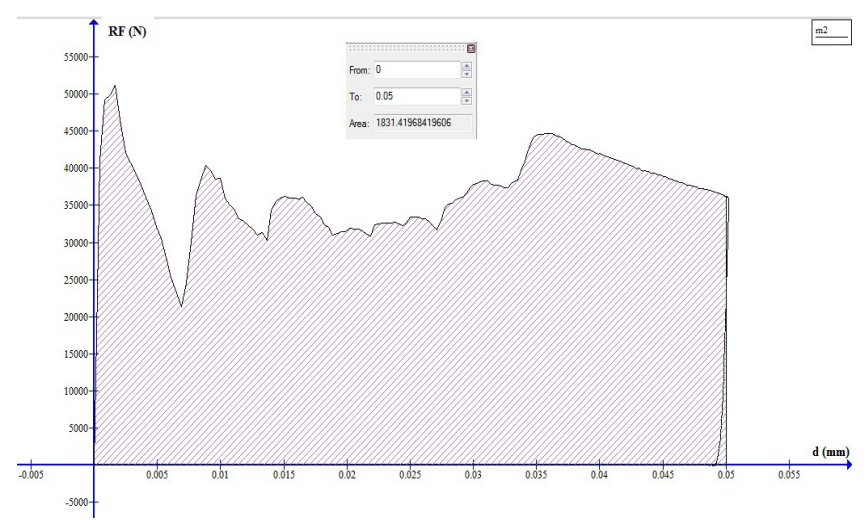

Figure 26. Force-displacement curve of $\mathrm{C} 2$.

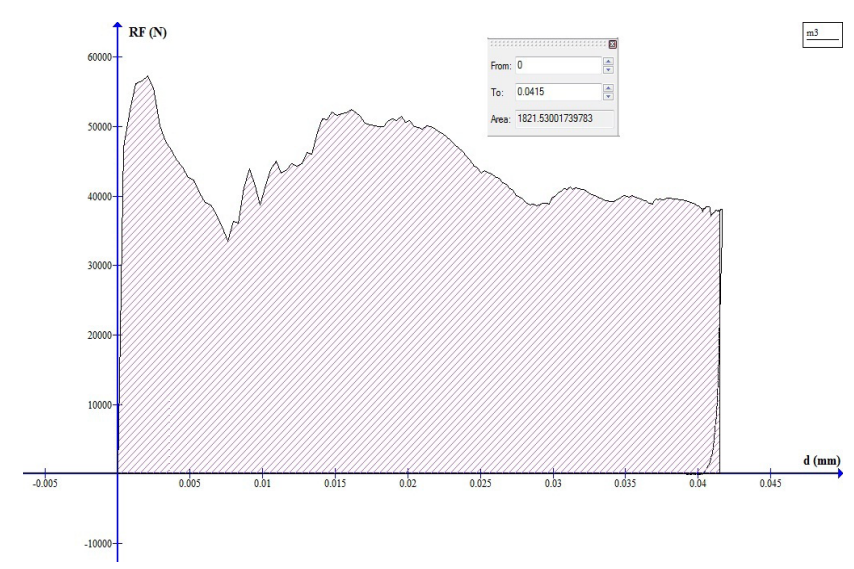

Figure 27. Force-displacement curve of C3.

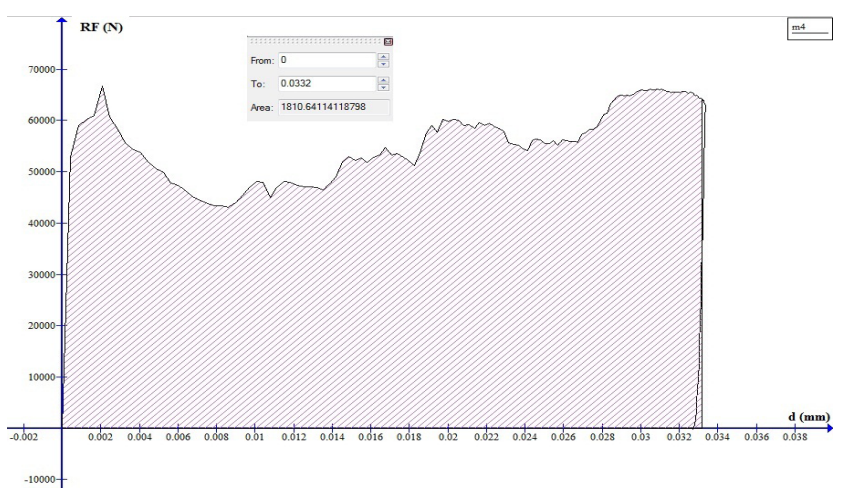

Figure 28. Force-displacement curve of C4.

test specimens), the most appropriate absorber must be selected in the impact loading.

For comparing the test specimens in order to select the suitable absorber, initial peak force and crush length are suitable parameters for this purpose because the loading is in the impact form and the absorbed energy is the same 
for all specimens and the average force behavior of the specimens is like their initial peak force behavior. In the same absorbed energy, if initial peak force is less, the structures at the back of absorbers will damage less. Therefore, among the specimens, the conical absorber is better than the cylindrical one because the initial peak force of the $\mathrm{C} 4$ absorber is equal to that of the $\mathrm{S} 0$ absorber. Moreover, in the discussion of absorber design, if there is required space for deformation, the crush length parameter can be used and instead, initial peak force can be decreased. For this situation, $\mathrm{C} 0$ with the lowest initial peak force has the highest crush length and half of the specimen length is compressed. Therefore, in the design of absorbers under impact loading, if there is a limited space, the $\mathrm{C} 4$ specimen will be the most appropriate absorber. And if there is no space limitation in the design, the $\mathrm{C} 0$ specimen will be the most appropriate absorber.

\section{Conclusion}

Studies were carried out on the specimens of alloy steel with cylindrical and conical sections with and without longitudinal reinforcements under free-fall impact loading. The obtained results based on experimental and numerical results and the use of the acceleration-time, velocity-time, and displacement-time curves, especially the force-displacement curve and the absorbed energy value are as follows:

- The absorbed energy values of test specimens under free-fall impact loading are equal due to the same height and the same impacting mass.

- The initial peak force, average force and slowing acceleration increase with the increasing number of longitudinal reinforcements.

- The crush length value decreases with the increasing number of longitudinal reinforcements.

- Cylindrical specimens have a higher initial peak force and average force than conical ones with the same number of reinforcements.

- Conical specimens have a higher crush length than cylindrical one with the same number of reinforcements.

- Finally, based on the comparison of the results obtained under different parameters in the design of energy absorbers under free-fall impact loading, if there is a limited space, the conical specimen with four longitudinal reinforcements (C4) will be the best specimen.
If there is no space limitation in the design, the conical specimen without longitudinal reinforcement (C0) will be the best energy absorber under free fall loading.

\section{References}

1. Zhang X, Cheng G. Energy absorption of axially compressed thin-walled square tubes with patterns. Thin Wall Struct. 2007; 45(9):737-46.

2. Nagel GM, Thambiratnam DP. Computer simulation and energy absorption of tapered thin-walled rectangular tubes. Thin-Walled Struct. 2005; 45(8):1225-42.

3. Reid S. Plastic deformation mechanisms in axially compressed metal tubes used as impact energy absorbers. Int J Mech Sci. 1993; 35:1035-52.

4. Wierzbicki T, Abramowicz W. On the crushing mechanics, thin-walled structures. J Appl Mech Trans ASME. 1983; 50(4a):727-34.

5. Abramowicz W, Wierzbicki T. Axial crushing of multi corner sheet metal columns, J Appl Mech Trans ASME. 1986; 56(1):113-20.

6. Abramowicz W, Jones N. Dynamic axial crushing of square tubes. Int J Impact Eng. 1984; 2:179-208.

7. Abramowicz W, Jones N. Dynamic progressive buckling of circular and square tubes. Int J Impact Eng. 1986; 4(4):243-70.

8. Nagel GM, Thambiratnam DP. A numerical study on the impact response and energy absorption of tapered, thinwalled tubes. Int J Mech Sci. 2004; 46(2):201-16.

9. Nagel GM, Thambiratnam DP. Dynamic simulation and energy absorption of tapered thin-walled tubes under oblique impact loading. Int J Impact Eng. 2006; 32(10):1595-620.

10. Hanssen AC, Langseth M, Hopperstad OS. Static and dynamic crushing of circular aluminium extrusions with aluminium foam filler. Int J Impact Eng. 2000; 24(5):475-507.

11. Reyes A, Langseth M, Hopperstad OS. Crashworthiness of aluminum extrusions subjected to oblique loading: experiments and numerical analyses. Int J Mech Sci. 2002; 44:1965-84.

12. Olabi AG, Morris E, Hashmi MSJ. Metallic tube type energy absorbers: asynopsis. Thin Wall Struct. 2007; 45(78):706-26.

13. Tai YS, Huang MY, Hu HT. Axial compression and energy absorption characteristic s of high-strength thin-walled cylinders under impact load. Theor Appl Fract Mec. 2010; 53:1-8.

14. Di Paolo BP, Monteiro PJM, Gronsky R. Quasi-static axial crush response of a thin-wall stainless steel box component. Int J Solids Struct. 2004; 41:3707-33. 
15. Zhang X, Huh H. Energy absorption of longitudinally grooved square tubes under axial compression. Thin Wall Struct. 2009; 47:1469-77.

16. Zhang XW, Tian QD, Yu TX. Axial crushing of circular tubes with buckling initiators. Thin Wall Struct. 2009; 47(6-7):788-97.
17. Zhang XW, Su H, Yu TX. Energy absorption of an axially crushed square tube with a buckling initiator. Int J Impact Eng. 2009; 36:402-17.

18. Tang Z, Liu S, Zhang Z. Energy absorption properties of non-convex multi corner thin-walled columns. Thin Wall Struct. 2012; 51:112-20. 